\title{
To cut or not to cut: When is the pill mightier than the scalpel?
}

\author{
Alejandro C. Bribriesco, MD, Usman Ahmad, MD, and Siva Raja, MD, PhD
}

\footnotetext{
From the Department of Thoracic and Cardiovascular surgery, Heart and Vascular Institute, Cleveland Clinic Cleveland, Ohio.

Disclosures: Authors have nothing to disclose with regard to commercial support.

Received for publication Jan 12, 2018; accepted for publication Jan 23, 2018; available ahead of print March 7 , 2018.

Address for reprints: Siva Raja, MD, PhD, Cleveland Clinic Foundation, 9500 Euclid Ave J4-1, Cleveland, OH 44195 (E-mail: rajas@ccf.org).

J Thorac Cardiovasc Surg 2018;155:e199-200

$0022-5223 / \$ 36.00$

Copyright (c) 2018 by The American Association for Thoracic Surgery

https://doi.org/10.1016/j.jtcvs.2018.01.049
}

A mark of an experienced surgeon is knowing when not to operate. We are called to this specialty in part because of the opportunity to have an immediate positive impact on a patient's health. The saying "with great power, comes great responsibility" certainly applies to the decision to operate. This is one of the most difficult aspects for surgeons to learn: when to sheath the scalpel.

In this month's Journal, Nasser and colleagues ${ }^{1}$ present a case report in which medical therapy was effectively used to treat a disease for which surgery has been considered the mainstay of therapy. The case report describes the use of the mechanistic target of rapamycin inhibitor sirolimus to treat a woman with a large, symptomatic mediastinal lymphangioma. Although the rare nature of the disease precludes substantial experience to guide treatment, surgical excision has been uniformly required in the adult population. ${ }^{2}$ In this case, the creative off-label use of sirolimus was implemented after the failure of multiple nonsurgical treatments. The rationale was based on the understanding of lymphangiogenesis, with experience from the pediatric literature in which lymphangiomas are more common. This hypothesis proved correct, and the mass responded impressively, resulting in resolution of the lymphangioma and symptoms for the observed period of more than 3.5 years. Notably, this response was maintained despite discontinuation of the medication at posttreatment month 38 in response to the development of drug-induced pneumonitis.

Nasser and colleagues ${ }^{1}$ are to be commended for this contribution to the surgical literature, because it highlights key points in the evolution of disease therapy. The history of medicine and surgery contains several examples of shifts in the "standard of care," such as the establishment of effective pharmacologic therapy for gastric ulcers and the refinement of indications for percutaneous versus surgical coronary revascularization. ${ }^{3,4}$ The lessons learned from this singular case of mediastinal lymphangioma may not situations.

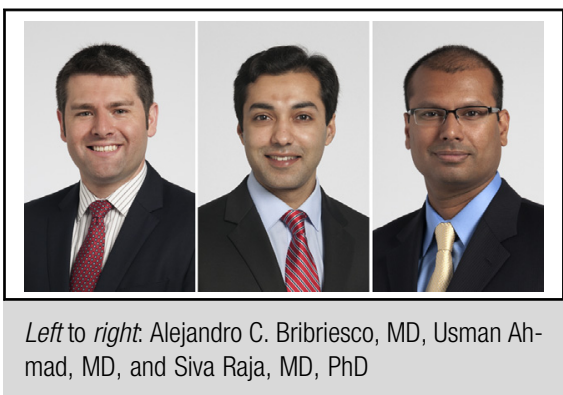

Central Message

Rare diseases require treatment strategies that are based on scientific evidence and clinical judgment. Medicine can supplant surgery in some cases, but operative intervention must be considered.

See Article page e195.

be widely applicable to other illnesses; however, the report highlights the continued need for pursuit of novel therapeutic strategies on the basis of the thoughtful application of basic science knowledge of a disease process coupled with multidisciplinary clinical experience. A potential example stemming from the experience of Nasser and colleages ${ }^{1}$ could be preoperative treatment to reduce the size of a mass to optimize complete surgical resection. Some cysts in adults are the result of recurrent tumors treated during childhood, and so "adjuvant" therapy with mechanistic target of rapamycin inhibitors is another extension of the results of this case report that future clinicians could consider in the event that they are faced with a challenging case of lymphangioma.

The choice to pursue conservative treatment in lieu of cold steel and hot lights is not always clear-cut. Medical therapy is not without complications, as evidenced here by sirolimus-induced pneumonitis. This case report underscores the importance of both medical and surgical teams weighing the risks of drug administration against the possible surgical complications when devising the most appropriate therapeutic strategy. Other considerations of pharmacologic treatment include long-term compliance (especially in young patients), the cost of the drug, and the patient's preference. In other words, available evidence and clinical judgment should always sharpen or sheath the scalpel, especially in uncommon 


\section{References}

1. Nasser M, Ahmad K, Cottin V. Mediastinal lymphangioma in an adult. J Thorac Cardiovasc Surg. 2018;155:e195-7.

2. Kavunkal AM, Ramkumar J, Gangahanumaiah S, Parimelazhagan KN, Cherian VK. Isolated mediastinal cystic lymphangioma in a child. J Thorac Cardiovasc Surg. 2007;134:1596-7.
3. Graham DY. History of Helicobacter pylori, duodenal ulcer, gastric ulcer and gastric cancer. World J Gastroenterol. 2014;20:5191-204.

4. King SB III, Marshall JJ, Tummala PE. Revascularization for coronary artery disease: stents versus bypass surgery. Аnnu Rev Med. 2010;61: 199-213. 